\title{
Experimental Evaluation of the Heat Output/Input and Coefficient of Performance Characteristics of a Chemical Heat Pump in the Periodic Operation of $\mathrm{CaCl}_{2}$ Hydration
}

\author{
Atsuhiro Ichinose, Kazuki Kuwata, Takehiro Esaki, Takayuki Matsuda, Noriyuki Kobayashi* \\ Nagoya University, Furo-cho, Chikusa-ku, Nagoya, Aichi, Japan \\ Email: *kobayashi@energy.gr.jp
}

How to cite this paper: Ichinose, A., Kuwata, K., Esaki, T., Matsuda, T. and Kobayashi, N. (2020) Experimental Evaluation of the Heat Output/Input and Coefficient of Performance Characteristics of a Chemical Heat Pump in the Periodic Operation of $\mathrm{CaCl}_{2}$ Hydration. Journal of Materials Science and Chemical Engineering, 8, 33-42.

https://doi.org/10.4236/msce.2020.811003

Received: May 23, 2020

Accepted: November 14, 2020

Published: November 17, 2020

Copyright $\odot 2020$ by author(s) and Scientific Research Publishing Inc. This work is licensed under the Creative Commons Attribution International License (CC BY 4.0).

http://creativecommons.org/licenses/by/4.0/ (c) (i) Open Access

\begin{abstract}
We herein evaluate the use of a chemical heat pump (CHP) for upgrading waste heat. $\mathrm{CaCl}_{2}$ was used in the system of $\mathrm{CHP}$. We evaluated the heat storage and heat releasing of CHP, and confirmed the practicality from the experimental results. The reactor module employed was an aluminum plate-tube heat exchanger with corrugated fins, and the $\mathrm{CaCl}_{2}$ powder was in the form of a packed bed. Heat storage operation and heat dissipation operation are performed at the same time and supplied to the heat demand destination. At this time, an environmental heat source can be used during the heat radiation operation, and the heat output can release more heat than the heat input during heat storage. The heat discharging and charging characteristics of the reactor module were evaluated experimentally. The coefficient of performance (COP) was calculated for the heat upgrading cycle, and the heat output in the system was determined. A COP of 1.42 and output of $650 \mathrm{~W} / \mathrm{L}$, based on the heat exchanger volume, were obtained using a $600 \mathrm{~s}$ change time for the heat pump.
\end{abstract}

\section{Keywords}

Chemical Heat Pump, $\mathrm{CaCl}_{2} / \mathrm{H}_{2} \mathrm{O}$ Hydration Reaction, Heat Pump Cycle, Coefficient of Performance

\section{Introduction}

The development of technologies and systems for enhancing energy efficiency to mitigate $\mathrm{CO}_{2}$ emissions has received increasing attention in recent years [1] [2] [3]. Utilizing waste heat discharged from industrial processes is one of the essen- 
tial issues for improving energy efficiency. Reducing the quantitative, temporal, topographic, and qualitative imbalances remaining between the heat supply and the heat demand is important for promoting heat energy utilization, and many thermal management technologies have been developed. For example, processes and technologies such as the organic rankine cycle [4], thermoelectric power generation [5] [6], heat pumps [7], sensible heat storage [8], and chemical heat pumps have been reported.

Among these technologies, the chemical heat pump (CHP), driven by reversible chemical reactions, is a promising technology for contributing to the need to utilize thermal energy. Studies have suggested a number of natural high-affinity refrigerant and reactant pairs, including $\mathrm{H}_{2} \mathrm{O}$ [9], $\mathrm{NH}_{3}$ [10], and $\mathrm{CO}_{2}$ [11] for refrigerants and solid oxides and metal halides for reactants. To date, CHPs have been investigated in a number of cycle modes, namely heat storage, heat upgrading, and chiller heat modes.

Many thermal applications using $\mathrm{CaCl}_{2}$ have been demonstrated extensively [12] [13]. This material has the outstanding features of low cost, nontoxicity, and thermochemical stability. The $\mathrm{CaCl}_{2} / \mathrm{H}_{2} \mathrm{O}$ reaction system has been studied for thermochemical heat storage, and the potential use of both the $\mathrm{CaCl}_{2} / \mathrm{H}_{2} \mathrm{O}$ reversible reactions has been demonstrated in previous studies [14] [15] [16].

For heat upgrading, we selected the hydration reaction of $\mathrm{CaCl}_{2}$ for a $\mathrm{CHP}$ reaction system, where the reversible hydration reaction is as follows:

$$
\mathrm{CaCl}_{2} \cdot \mathrm{H}_{2} \mathrm{O}+\mathrm{H}_{2} \mathrm{O} \leftrightarrow \mathrm{CaCl}_{2} \cdot 2 \mathrm{H}_{2} \mathrm{O}+52.7 \mathrm{~kJ} / \mathrm{mol}
$$

In this study, we examined the chemical heat pump shown in Figure 1. For each batch operation of the heat release operation and the heat storage operation, to constitute an increase of the heat pump mode, we evaluated the output performance using a laboratory scale reactor on the condition of assuming warm water output of around $90^{\circ} \mathrm{C}$. The output per volume of the reactor and the coefficient of performance (COP) were estimated from the result.

\section{Experimental and Calculation Approach}

\subsection{Experimental Set up}

A schematic drawing of the experimental setup is provided in Figure 2. The setup comprised three decompression chambers, an evaporator, a condenser, and a reactor with a heat storage module installed inside the reactor chamber. Each of these components was connected with vapor flow tubes. The components and vapor flow tubes were covered with glass wool and a combination of glass wool and electric heaters, respectively, to prevent vapor condensation or heat loss. Each component was also connected to a thermostat bath as a heat source. The heat-medium fluids supplied from the thermostat baths were circulated through the components. Figure 3 shows the corrugated aluminum fin-type heat exchanger used as the heat storage module in the experiments. The heat storage module had a whole volume of $1.1 \mathrm{~L}$ and measured $250 \mathrm{~mm} \times 200 \mathrm{~mm} \times 20 \mathrm{~mm}$ (without the header). The pitch of the fluid flow path was $8 \mathrm{~mm}$, and the pitch of 


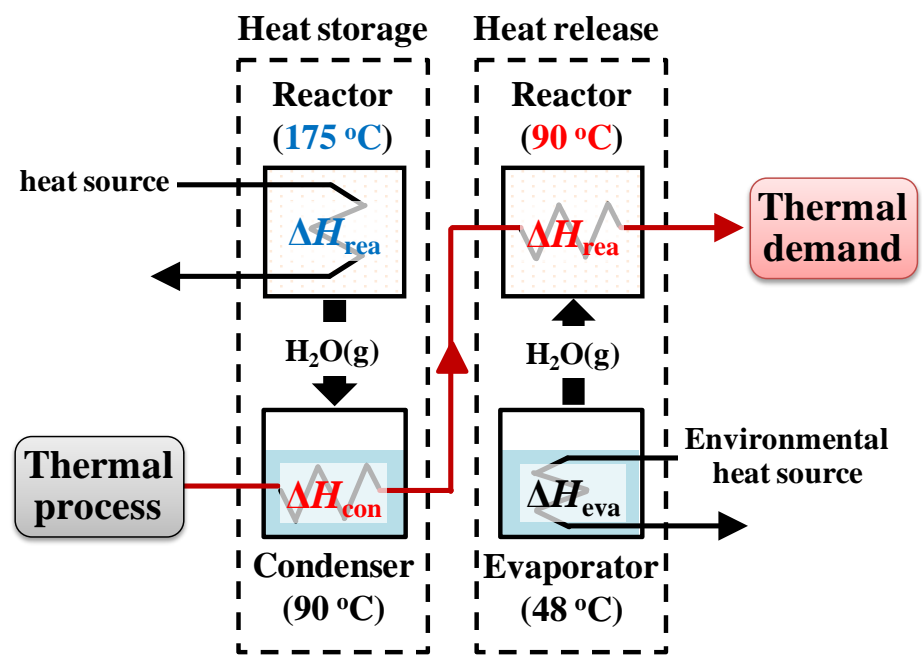

Figure 1. Schematic of the chemical heat pump.

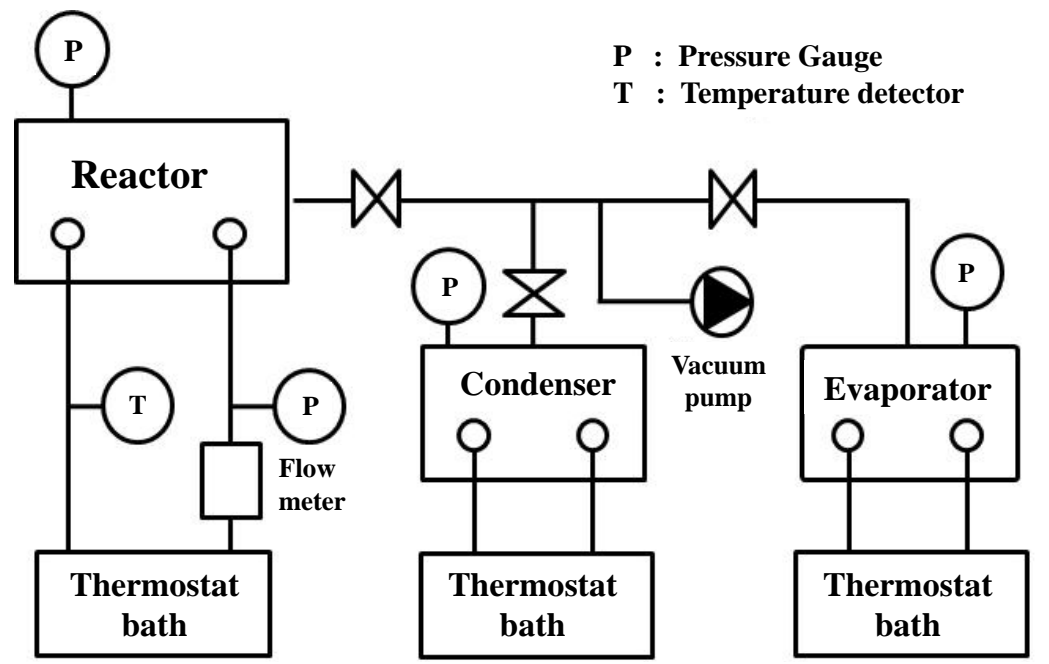

Figure 2. Schematic of the experimental apparatus.

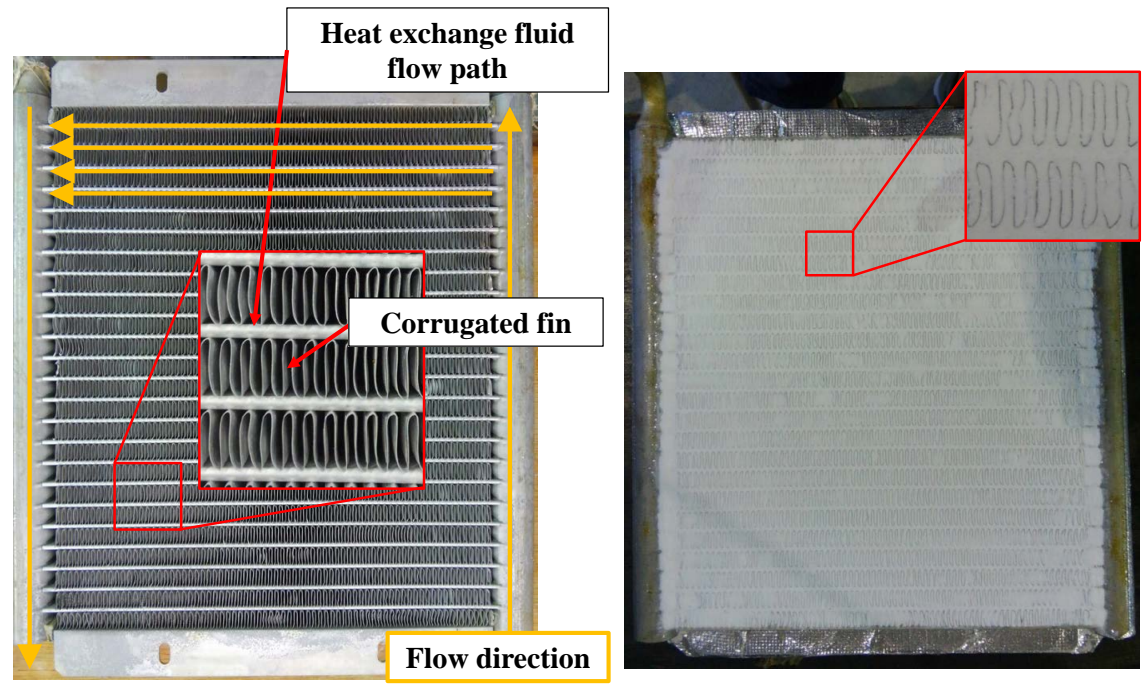

Figure 3. The corrugated aluminum fin-type heat exchanger. 
the corrugated fin was $3.0 \mathrm{~mm}$. The heat storage module was filled with $650 \mathrm{~g}$ of anhydrous $\mathrm{CaCl}_{2}$ particles, covered on the top and bottom with nickel mesh, and installed in the reactor chamber. The filling fraction based on the filling space was 0.42 . Reagent anhydrous $\mathrm{CaCl}_{2}$ particles (>95\% purity) were obtained from Wako Chemicals (Japan). The material was dried in an electric furnace at $180^{\circ} \mathrm{C}$ for 24 hours. The $\mathrm{CaCl}_{2}$ powder was homogenized by diameter $\left(d_{p}=125-250\right.$ $\mu \mathrm{m})$ before filling it into the heat storage module. As a final step before initiating the experiments, air was removed from the three components and the vapor flow tubes by vacuum pump.

In the following experiments, evaluation parameters were calculated based on the experimental results of the heat-medium fluid temperature and the flow rate through the reactor. The fluid temperatures at the heat storage module's inlet and outlet were measured using platinum resistance temperature detectors, and the fluid flow volume was measured using a turbine flow meter from Japan Flow Controls Co., Ltd. (Japan). Thermal H350 fluid, obtained from JULABO (Germany), was used as the heat-medium fluid in the reactor. Water was used in the evaporator and the condenser. The evaluation parameters, including average volumetric power density, $Q_{\text {ave, }}$ conversion ratio, $X$, and cumulative heat capacity, $Q_{\text {cum }}$, were calculated using following equations:

$$
\begin{gathered}
Q_{\text {cum }}=\frac{\int_{0}^{t} C_{p, f} \cdot \rho_{f} \cdot F \cdot \Delta T}{V_{\text {module }}} \\
X=\frac{\int_{0}^{t} C_{p, f} \cdot \rho_{f} \cdot F \cdot \Delta T}{\Delta H_{\text {theo }}} \\
Q_{\text {ave }}=\frac{Q_{\text {cum }}}{t}
\end{gathered}
$$

The discharging and charging conditions were selected assuming conversion of the low-temperature waste heat $\left(200^{\circ} \mathrm{C}\right)$ to heat-enhanced hot water (upward of $90^{\circ} \mathrm{C}$ ). Moreover, the reaction conditions were selected carefully because hysteresis effects have been reported in previous studies. As indicated in Figure 4 , the heat charging/discharging operation followed the reaction lines for the hydration and dehydration of $\mathrm{CaCl}_{2}$, as well as the experimental conditions (vapor pressure controlled by the evaporator or the condenser and inlet temperature of the heat-medium fluid tempering the reactor) used in this study (charging/discharging condition is denoted by white/black circles). During the discharging operation, the water vapor was transported from the evaporator to the reactor, where the exothermic reaction subsequently occurred. During the charging operation, the endothermic reaction charged the heat in the reactor and the released water vapor was transported to the condenser. Switching between the operations was implemented using the control valves on the vapor flow tubes. The flow rate of the heat-medium fluid for the reactor was $3.2 \mathrm{~L} / \mathrm{min}$ for both operations. 


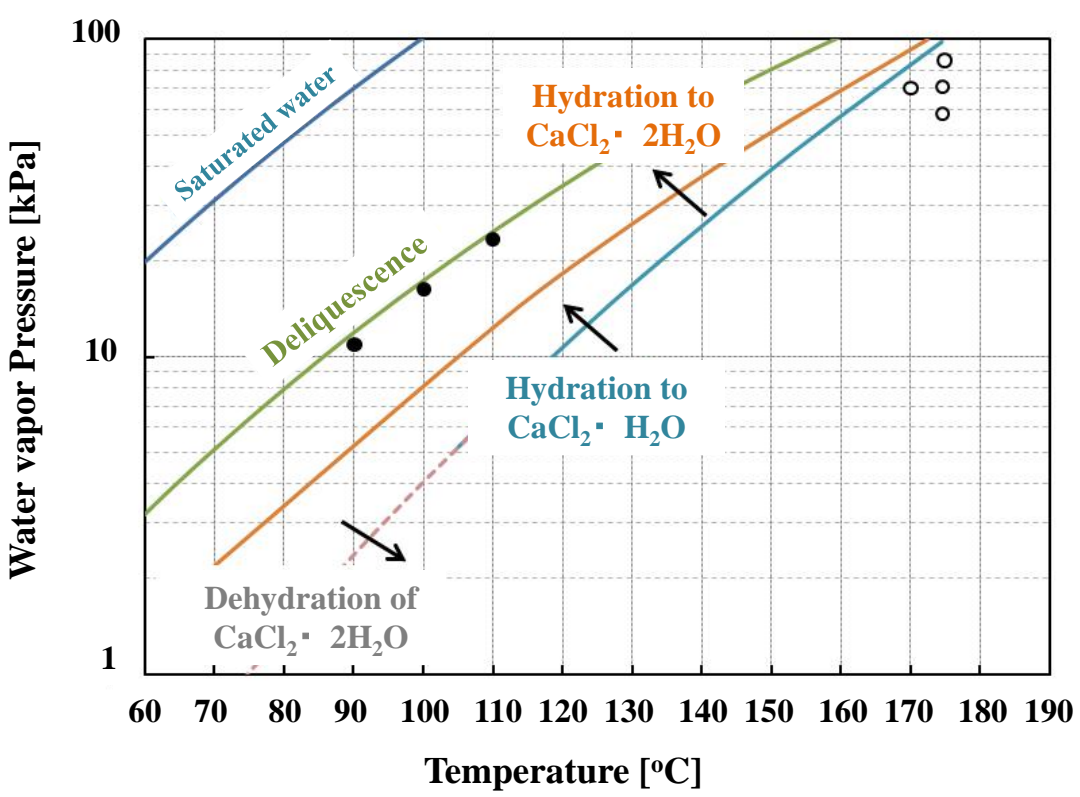

Figure 4. Thermochemical reaction lines and experimental conditions (charging/discharging condition is denoted by white/black circles).

\subsection{Calculation Method}

COP was calculated as the heat enhancement mode evaluation parameter of CHP, based on the discharging and charging operation results. The following equations were used for the calculation; $Q_{\text {storage }}$ means averaged volumetric power density for storage, $Q_{\text {release }}$ means averaged volumetric power density for discharging, $Q_{\text {output }}$ means averaged heat output, and $Q_{\text {input }}$ means averaged heat input. Moreover, the change in amount of sensitive heat was considered assuming switching control between the discharging and charging operations. Additionally, the switching control time was out of consideration.

$$
\begin{gathered}
Q_{\text {output }}=Q_{\text {release }}+\frac{\Delta H_{\text {con }}}{\Delta H_{\text {rea }}} \cdot\left(-Q_{\text {storage }}\right) \\
Q_{\text {input }}=Q_{\text {storage }} \\
\mathrm{COP}=\frac{\Delta Q_{\text {output }} \cdot t+\left(C_{\text {p_lhyd }}+C_{\text {p_Al }}\right)}{\Delta Q_{\text {input }} \cdot t+\left(C_{\text {p_2hyd }}+C_{\text {p_Al }}\right)}
\end{gathered}
$$

\section{Results and Discussion}

The discharging operation assuming the hot water output was demonstrated. Figure 5 shows the measurement result of the discharging operation at the reactor $\left(90^{\circ} \mathrm{C}\right)$ and evaporator $\left(48^{\circ} \mathrm{C}\right)$. The temperature of the heat-medium fluid flowing through the reactor rose from $90^{\circ} \mathrm{C}$ to $98^{\circ} \mathrm{C}$.

Figure 6 shows time course of the averaged power density. The conversion ratio, shown in Figure 5, reached 0.8 after $600 \mathrm{~s}$ ( $350 \mathrm{~W} / \mathrm{L}$-reactor). The reaction rate is calculated from the temperature difference between the inlet and outlet of the heat exchange fluid. The heat of reaction is released to the environment in 


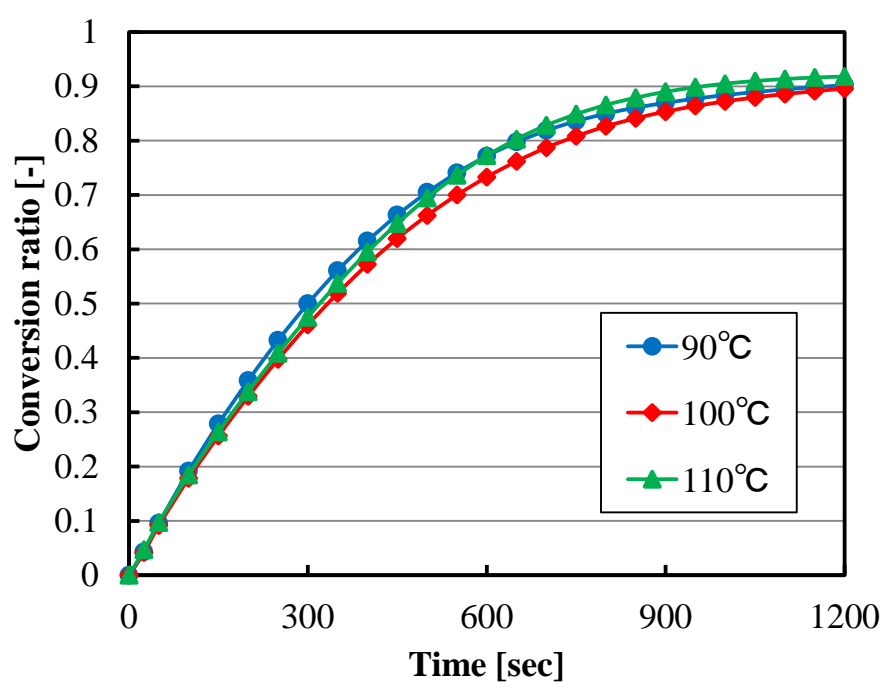

Figure 5. Conversion ratio in the discharging operation at several temperatures of the reactor.

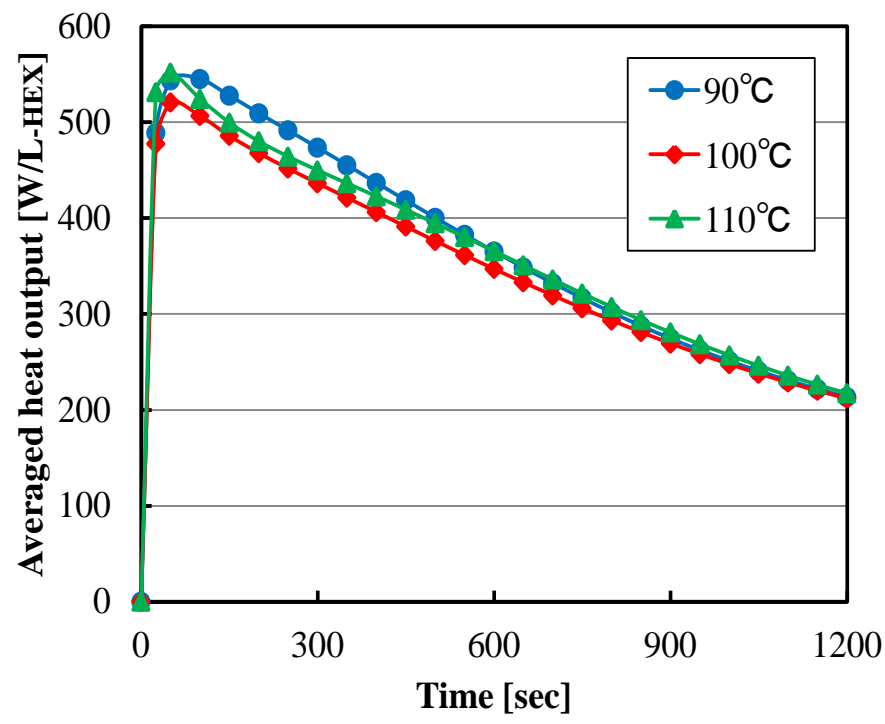

Figure 6. Averaged heat output in the discharging operation at several temperatures of the reactor.

addition to the heat transfer to the heat exchange fluid. Therefore, it is considered that the reaction rate has not reached 1 . The change in the results caused by reactor temperature was small, so the influence of reactor temperature was confirmed to be small.

Figure 7 shows the experimental results of the charging operations. The conversion reached 0.8 at the reaction time of $600 \mathrm{~s}\left(350 \mathrm{~W} / \mathrm{L}-\right.$ reactor) at $175^{\circ} \mathrm{C}$, which is 2.9 times higher than the result with the reactor temperature of $170^{\circ} \mathrm{C}$. The condenser temperature also affected the heat charging behavior (Figure 8). The charging operation progressed at even $95^{\circ} \mathrm{C}$, so it was confirmed that the heat pump mode can be operated for a heat output of more than $90^{\circ} \mathrm{C}$. The charging rate showed a remarkable increase with decreasing condenser temperature. 


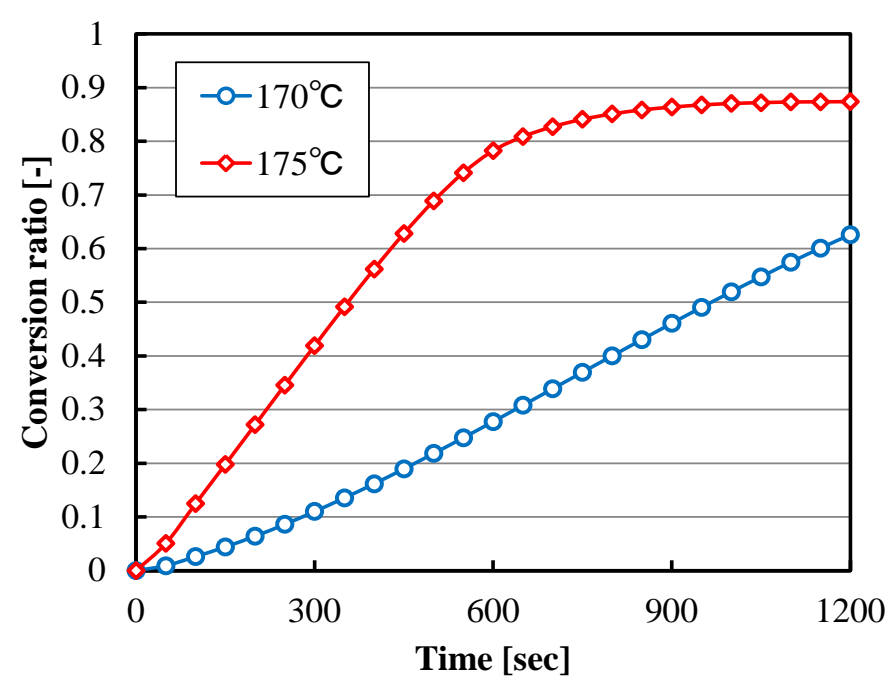

Figure 7. Conversion ratio at several temperatures of the reactor.

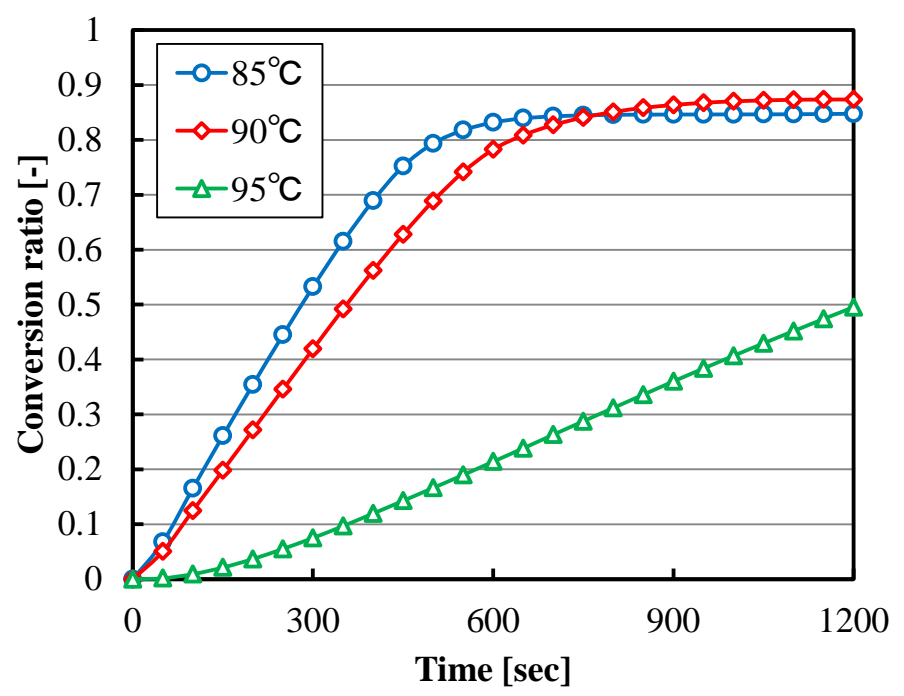

Figure 8. Conversion ratio at several temperatures of the condenser $\left(T_{\text {rea }}=175^{\circ} \mathrm{C}\right)$.

The conversion ratio reached 0.8 after $600 \mathrm{~s}$ at the condenser temperatures of $85^{\circ} \mathrm{C}$ and $90^{\circ} \mathrm{C}$. Condenser temperature at lower than $90^{\circ} \mathrm{C}$ is required for the practical charging rate.

We then calculated the variations in $Q_{\text {output }}, Q_{\text {input }}$, and COP with the time. The temperature conditions for the calculation follow: charging, $175^{\circ} \mathrm{C}$; discharging, $90^{\circ} \mathrm{C}$; evaporator, $48^{\circ} \mathrm{C}$; condenser, $90^{\circ} \mathrm{C}$.

Conversion ratio is calculated from Equation (3), and the heat of reaction is radiated outside the reactor in addition to the heat exchange fluid, so Conversion ratio has not reached 1.

As shown in Figure 9, $Q_{\text {output }}$ is higher than $Q_{\text {input }}$ during operation, so the heat pump mode was confirmed. The instant heat output performance showed a peak value of more than $Q_{\text {output }}=800 \mathrm{~W} / \mathrm{L}$-reactor, then $Q_{\text {output }}$ decreased through the remaining time. By contrast, $\mathrm{COP}$ increased with increasing time. 


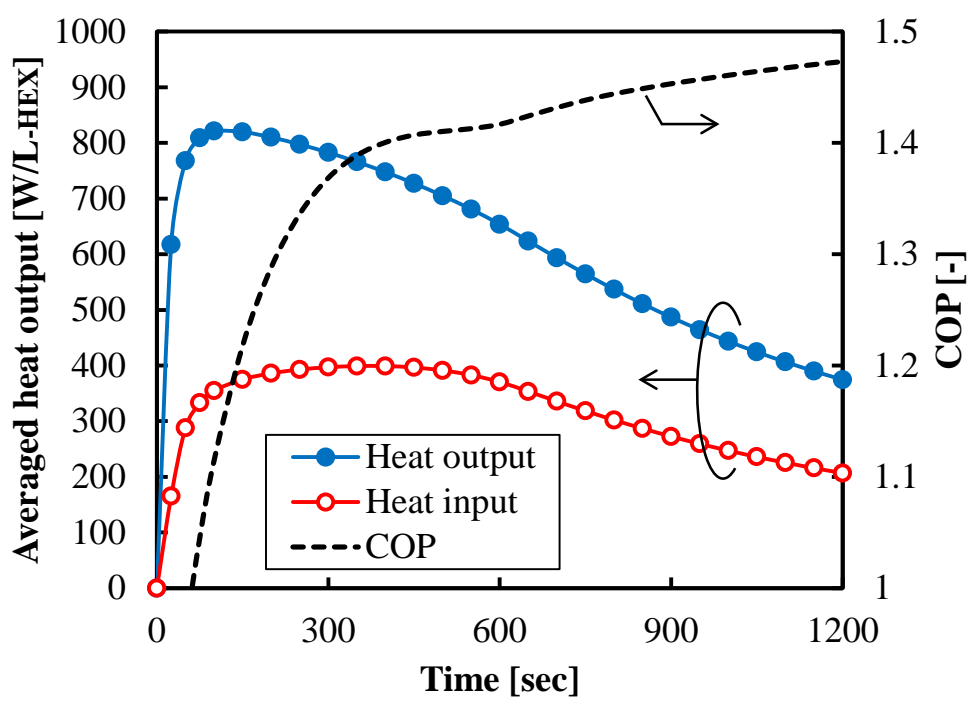

Figure 9. COP and averaged heat output in the heat pump system.

In actual use, it is assumed that the switching time of discharging and charging would be controlled to balance the reaction rate. Therefore, an output of 650 W/L-HEX and performance of COP 1.42 are shown at $600 \mathrm{~s}$. At this time, the reaction is changed from discharging to charging.

The average output decreases and the COP increases after the arrival of the peak for the remaining amount of elapsed time. Therefore, COP has a trade-off relation with the average output. The change of COP with the average output after arrival of the peak is shown Figure 10. When the average output reaches the peak of $700 \mathrm{~W} / \mathrm{L}$-HEX, COP decreases suddenly. For performance enhancement, improvement of the heat and COP should be analyzed. It is necessary to consider the diffusion of water vapor and the promotion of heat transfer for designing the reactor. It is possible that the state of the packed bed changes due to repeated operations of hydration and dehydration reactions, which affects the performance of CHP. Such thermochemical storage systems show strong deactivation. Especially hydration reactions of alkaline earth chlorides lead to a fusion of the particles, which enhances pressure drop and makes the core of the particle inaccessible [16]. The unevenness of water vapor pressure in packed bed is considered. Water vapor does not easily reach deep inside the packed bed, and it is possible that the hydration rate of $\mathrm{CaCl}_{2}$ decreases. A research on a heat pump system using calcium sulfate as a heat storage material has been reported [13]. It is known that the diffusion rate of water vapor in the packed bed affects the performance of heat output. Therefore, the maximum value of heat output is tripled by providing a structure for promoting water vapor diffusion.

\section{Conclusions}

We evaluated output performance using a laboratory scale reactor with the condition of assuming a warm water output of around $90^{\circ} \mathrm{C}$. The output per volume of reactor and the $\mathrm{COP}$ were estimated from the result. 


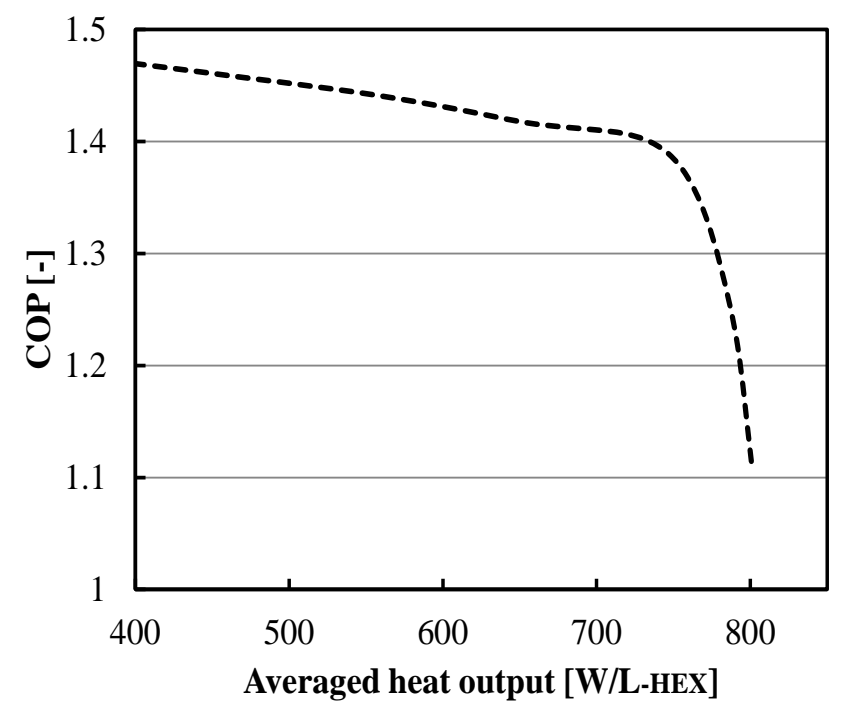

Figure 10. Change of COP with average output after the peak arrival.

When the periods of heat storage and heat release were switched at $600 \mathrm{~s}$, an average output of $650 \mathrm{~W} / \mathrm{L}-\mathrm{HEX}$ and a COP of 1.42 were obtained. When the average output reaches the peak of $700 \mathrm{~W} / \mathrm{L}-\mathrm{HEX}, \mathrm{COP}$ decreases suddenly. For performance enhancement, improvement of the heat and COP should be analyzed. This system is needed to be scaled up for practical use. Some problem is considered. In the future, we plan to design a device that promotes the diffusion of water vapor in the packed bed.

\section{Acknowledgements}

This research is supported by "Knowledge Hub Aichi", Priority Research Project from Aichi Prefectural Government, Japan. We also would like to thank Editage (https://WWW.editage.jp/) for English language editing.

\section{Conflicts of Interest}

The authors declare no conflicts of interest regarding the publication of this paper.

\section{References}

[1] Malik, A.S., Boyko, O., Atkar, N. and Young, W.F. (2001) A Comparative Study of MR Imaging Profile of Titanium Pedicle Screws. Acta Radiologica, 42, 291-293. https://doi.org/10.1080/028418501127346846

[2] Hu, T. and Desai, J.P. (2004) Soft-Tissue Material Properties under Large Deformation: Strain Rate Effect. Proceedings of the 26th Annual International Conference of the IEEE EMBS, San Francisco, 1-5 September 2004, 2758-2761.

[3] Ortega, R., Loria, A. and Kelly, R. (1995) A Semiglobally Stable Output Feedback PI2D Regulator for Robot Manipulators. IEEE Transactions on Automatic Control, 40, 1432-1436. https://doi.org/10.1109/9.402235

[4] Sun, W., Yue, X. and Wang, Y. (2017) Exergy Efficiency Analysis of ORC (Organic Rankine Cycle) and ORC-Based Combined Cycles Driven by Low-Temperature 
Waste Heat. Energy Conversion and Management, 135, 63-73. https://doi.org/10.1016/j.enconman.2016.12.042

[5] Wang, Y., Gai, L., Peng, W., Zhou, Y. and Chen, J. (2017) Maximal Continuous Power Output and Parametric Optimum Design of an Electrochemical System Driven by Low-Grade Heat. Energy Conversion and Management, 138, 156-161. https://doi.org/10.1016/j.enconman.2017.01.045

[6] Steward, F.R. (1984) Optimum Arrangement and Use of Heat Pumps in Recovering Waste Heat. Energy Conversion and Management, 24, 123-129. https://doi.org/10.1016/0196-8904(84)90023-2

[7] Sorour, M.M. (1988) Performance of a Small Sensible Heat Energy Storage Unit. Energy Conversion and Management, 28, 211-217. https://doi.org/10.1016/0196-8904(88)90024-6

[8] Mastronardo, E., Bonaccorsi, L., Kato, Y., Piperopoulos, E. and Milone, C. (2016) Efficiency Improvement of Heat Storage Materials for $\mathrm{MgO} / \mathrm{H}_{2} \mathrm{O} / \mathrm{Mg}(\mathrm{OH})_{2}$ Chemical Heat Pumps. Applied Energy, 162, 31-39. https://doi.org/10.1016/j.apenergy.2015.10.066

[9] Heard, C.L., Rivera, W. and Best, R. (2016) Characteristics of an Ammonia/Litium Nitrate Double Effect Heat Pump-Transformer. Applied Thermal Engineering, 99, 518-527. https://doi.org/10.1016/j.applthermaleng.2016.01.031

[10] Morgan, B., Wilson, S.A., Madsen, I.C., Gozukara, Y.M. and Habsud, J. (2015) Increased Thermal Stability of Nesquehonite $\left(\mathrm{MgCO}_{3} 3 \mathrm{H}_{2} \mathrm{O}\right)$ in the Presence of $\mathrm{Hu}$ midity and $\mathrm{CO}_{2}$, Implications for Low-Temperature $\mathrm{CO}_{2}$ Storage. International Journal of Greenhouse Gas Control, 39, 366-376. https://doi.org/10.1016/j.ijggc.2015.05.033

[11] Kuwata, K., Esaki, T., Yasuda, M., Matsuda, T., Kobayashi, N. and Shiren, Y. (2017) Durability of Thermochemical Heat Storage Demonstrated through Long-Term Repetitive $\mathrm{CaCl}_{2} / \mathrm{H}_{2} \mathrm{O}$ Reversible Reactions. Journal of Renewable and Sustainable Energy, 9, Article ID: 024102. https://doi.org/10.1063/1.4978351

[12] Shiren, Y., Masuzawa, M., Takahashi, T., Yamada, S., Hayakawa, K., Motohashi, Y., Aman, Y., Esaki, T. and Kobayashi, N. (2020) Thermal Input/Output and Operation Characteristics of a Chemical Heat Pump Using the Hydration Reaction of Calcium Sulphate. Sustainable Energy Fuels, 4, 4046-4056. https://doi.org/10.1039/D0SE00500B

[13] Molenda, M., Stengler, J., Linder, M. and Wörner, A. (2013) Reversible Hydration Behavior of $\mathrm{CaCl}_{2}$ at High $\mathrm{H}_{2} \mathrm{O}$ Partial Pressures for Thermochemical Energy Storage. Thermochimica Acta, 560, 76-81. https://doi.org/10.1016/j.tca.2013.03.020

[14] Molenda, M., Stengler, J. and Linder, M. (2016) Heat Transformation Based on $\mathrm{CaCl}_{2} / \mathrm{H}_{2} \mathrm{O}$-Part A: Closed Operation Principle. Applied Thermal Engineering, 102, 615-621. https://doi.org/10.1016/j.applthermaleng.2016.03.076

[15] Bouché, M., Richter, M. and Linder, M. (2016) Heat Transformation Based on $\mathrm{CaCl}_{2} / \mathrm{H}_{2} \mathrm{O}$-Part B: Open Operation Principle. Applied Thermal Engineering, 102, 641-647. https://doi.org/10.1016/j.applthermaleng.2016.03.102

[16] Kohler, T., Biedermann, T. and Muller, K. (2018) Experimental Study of $\mathrm{MgCl}_{2} 6 \mathrm{H}_{2} \mathrm{O}$ as Thermochemical Energy Storage Material. Energy Technology, 6, 1935-1940. 